\title{
Qualitative and Quantitative Analysis of Off-Shore Wind Energy Project's Risks
}

\author{
Sayed Amir Hamzeh Mirkheshti and Majid Feshari
}

Kharazmi University, Tehran, Iran

Correspondence should be addressed to Sayed Amir Hamzeh Mirkheshti; amirmirkheshti@gmail.com

Received 1 May 2017; Revised 1 August 2017; Accepted 20 September 2017; Published 24 October 2017

Academic Editor: Ching-Yuan Chang

Copyright ( 2017 Sayed Amir Hamzeh Mirkheshti and Majid Feshari. This is an open access article distributed under the Creative Commons Attribution License, which permits unrestricted use, distribution, and reproduction in any medium, provided the original work is properly cited.

\begin{abstract}
The benefits of wind power can solve the issue of growing power consumption with insufficient distribution facilities. Based on an extensive research on more than 20 studies, this study explores the risks associated with off-shore wind energy in Persian Gulf in Iran. This paper tries to identify the risks in related off-shore wind energy project, in order to specify which variables have the most impact on project by qualitative analysis through application of the impact and the possibility of every risk. A survey was conducted in order to determine the relative importance of variables and risks. Certain key components in completion of the project should be taken into account such as technology, research team, expert teams (personnel that have a good knowledge of this industry), and choosing the right spot where the wind farms will be located. The objective of this paper is to present the variables encountered in wind power project and to highlight the risks that must be controlled by the project developers, project team, supply chain actors, manufacturers, and all the stockholders involved in successful completion of a project.
\end{abstract}

\section{Introduction}

Wind power not only brings economic benefits but also helps to protect the environment that is becoming increasingly precarious due to globalization [1].

There are several impediments in further wide scale deployment of off-shore wind power; however, manufacturers are moving ahead with planned investments in production with the expectation that the market will grow in the future.

Off-shore wind projects often require larger investments and come with a greater risk of cost overrun both during the construction and in the operational phase of the wind turbine's life cycle.

Many companies withdraw quantitative analysis due to costly and time consuming process of analysis.

$\mathrm{PMBOK}$, which is the standard reference of project management, has defined four variables for each risk including impact, possibility, period of time, and frequency. In this standard, the effects of cost, time, and quality all are merged and are defined as impact. As a result, the separate weight of cost, time, and quality is diminished. One of the other caveats of this standard is that the number of repetition of each risk is considered as one, no matter how many times it is repeated. Also, the duration of each risk is considered as the duration of the whole project, even if the risk has happened in a short period of time in the whole project. In this standard, the weight of impact and possibility are identical.

Shirgholami et al. [2] has presented a practical approach to select the turbine that best matches the wind characteristics of a specific site among the commercially available ones. In their assessment of wind turbines, a complex process is considered that involves different criteria with different degrees of importance such as, economic, technological, and environmental ones.

Sagbansua and Balo [3] are constructed to choose a convenient turbine from various perspectives for developing a wind energy station. For $2 \mathrm{MW}$, the best wind turbine brands are listed based on expert interviews and literature review and they are used to establish a decision-making model with four main criteria consisting of technical, economic, environmental, and customer attributes with various subcriteria. The 
TABLE 1: Risk classification.

\begin{tabular}{|c|c|c|c|c|c|c|}
\hline $\begin{array}{l}\text { (1) Strategic, } \\
\text { business risk }\end{array}$ & $\begin{array}{l}\text { (2) Transport - } \\
\text { construction, } \\
\text { completion risks }\end{array}$ & $\begin{array}{l}\text { (3) Operation, } \\
\text { maintenance } \\
\text { risks }\end{array}$ & $\begin{array}{l}\text { (4) Liability, } \\
\text { legal risks }\end{array}$ & $\begin{array}{l}\text { (5) Market, } \\
\text { sales risks }\end{array}$ & $\begin{array}{l}\text { (6) Counterparty } \\
\text { risks }\end{array}$ & $\begin{array}{c}\text { (7) Political } \\
\text { policy, regulatory } \\
\text { risks }\end{array}$ \\
\hline $\begin{array}{l}\text { (i) Insufficient } \\
\text { access }\end{array}$ & $\begin{array}{l}\text { (i) Grid } \\
\text { connection }\end{array}$ & $\begin{array}{l}\text { (i) Technology } \\
\text { limitation }\end{array}$ & $\begin{array}{l}\text { (i) Damage to } \\
\text { environment }\end{array}$ & (i) Resource & $\begin{array}{l}\text { (i) Supplier- } \\
\text { contractor }\end{array}$ & (i) Change rules \\
\hline $\begin{array}{l}\text { (ii) Technology } \\
\text { and innovation }\end{array}$ & $\begin{array}{l}\text { (ii) Damage or } \\
\text { theft during } \\
\text { transport or } \\
\text { construction }\end{array}$ & $\begin{array}{l}\text { (ii) Maritime } \\
\text { environment }\end{array}$ & $\begin{array}{l}\text { (ii) Complex } \\
\text { approval } \\
\text { processes }\end{array}$ & (ii) Curtailment & $\begin{array}{l}\text { (ii) Buyer (power } \\
\text { purchase } \\
\text { agreement) }\end{array}$ & $\begin{array}{l}\text { (ii) Risk of war, } \\
\text { terrorism and }\end{array}$ \\
\hline $\begin{array}{l}\text { (iii) Insufficient } \\
\text { expertise }\end{array}$ & $\begin{array}{l}\text { (iii) Special } \\
\text { construction } \\
\text { vessels }\end{array}$ & $\begin{array}{l}\text { (iii) Natural } \\
\text { hazards }\end{array}$ & $\begin{array}{l}\text { (iii) Property } \\
\text { damage and } \\
\text { bodily injures }\end{array}$ & $\begin{array}{l}\text { (iii) Price } \\
\text { volatility }\end{array}$ & (iii) Guaranty & \\
\hline \multirow[t]{4}{*}{$\begin{array}{l}\text { (iv) Insufficient } \\
\text { public } \\
\text { acceptance }\end{array}$} & $\begin{array}{l}\text { (iv) Quality of } \\
\text { materials \& spare } \\
\text { part }\end{array}$ & $\begin{array}{l}\text { (iv) Design and } \\
\text { quality of } \\
\text { foundation }\end{array}$ & & & & \\
\hline & $\begin{array}{l}\text { (v) Transportation } \\
\text { equipment }\end{array}$ & $\begin{array}{l}\text { (v) Repair, } \\
\text { replacement }\end{array}$ & & & & \\
\hline & $\begin{array}{l}\text { (vi) Assembling } \\
\text { and installation }\end{array}$ & $\begin{array}{l}\text { (vi) Turbine } \\
\text { performance }\end{array}$ & & & & \\
\hline & $\begin{array}{l}\text { (vii) Quality of } \\
\text { raw material }\end{array}$ & $\begin{array}{l}\text { (vii) Delays in } \\
\text { repair }\end{array}$ & & & & \\
\hline
\end{tabular}

selection of the best wind turbine is determined by using AHP technique.

Chaouachi et al. [4] presented a multicriteria selection approach for off-shore wind sites assessment. The proposed site selection framework takes into consideration the electricity network's operating security aspects, economic investment, operation costs, and capacity performances relative to each potential site. The selection decision is made through AHP, aiming to allow decision makers (investors, regulatory authorities, and electricity network operators) to adjust the selectivity weighting to reflect their respective and global priorities. Their approach used for arbitration among the potential projects takes into consideration operational challenges of wind power integration by reflecting the physical impact of power infeeds on the electricity networks. The physical impact on the electricity network includes operating security aspects, economic investment, operation costs, and adequacy contribution relative to each potential site.

In our proposed model, we had considered six variables comprising possibility, cost, time, frequency, quality, and period of time. Frequency means the number of the repetitions of a risk in a project; more frequency means greater weight. Cost shows the extra expenditure imposed by each risk. Time signifies the delayed scheduling due to each risk. Possibility shows contingency of the occurrence of each risk in the whole project. Quality assesses the effect of each risk on the quality of every deliverable. And finally, period of time shows the period of each risk. Whatever it would be wider and closer to the end of project, its weight would be higher.

Weight of each risk factor such as probability, time, and cost is not constant and these factors' weight will be changing based on politics, the place at which the project is performed, and so on.
TABLE 2: Final weight of variables.

\begin{tabular}{lc}
\hline Risk factor & Overall weight \\
\hline Period of Time & 0.038 \\
Frequency & 0.059 \\
Quality (project) & 0.115 \\
Time (project) & 0.2 \\
Cost (Project) & 0.52 \\
Possibility & 0.068 \\
\hline Inconsistency & 0.08 \\
\hline
\end{tabular}

This study was conducted with the following six steps:

(1) To identify the risks that developers faced in off-shore wind energy project and to categorize them (Table 1).

(2) To perform qualitative analysis in order to determine the more important risks in the whole project.

(3) To elaborate the decision hierarchy after the decision is decomposed into its independent elements including variables and alternatives (Figure 1).

(4) To perform quantitative analysis by using AHP and To specify final weight of each variable (Table 2).

(5) Doing pairwise comparison alternatives (risk) in related each risk factor to signify final weights of alternatives across variables (Table 3 ).

(6) Calculate the final weights of each alternative based on relative importance (Table 4) and performance sensitivity alternatives across variables (Figure 2 ).

These models aim at sustainable decisions and at ancrease in management capabilities so that methods in order to face 


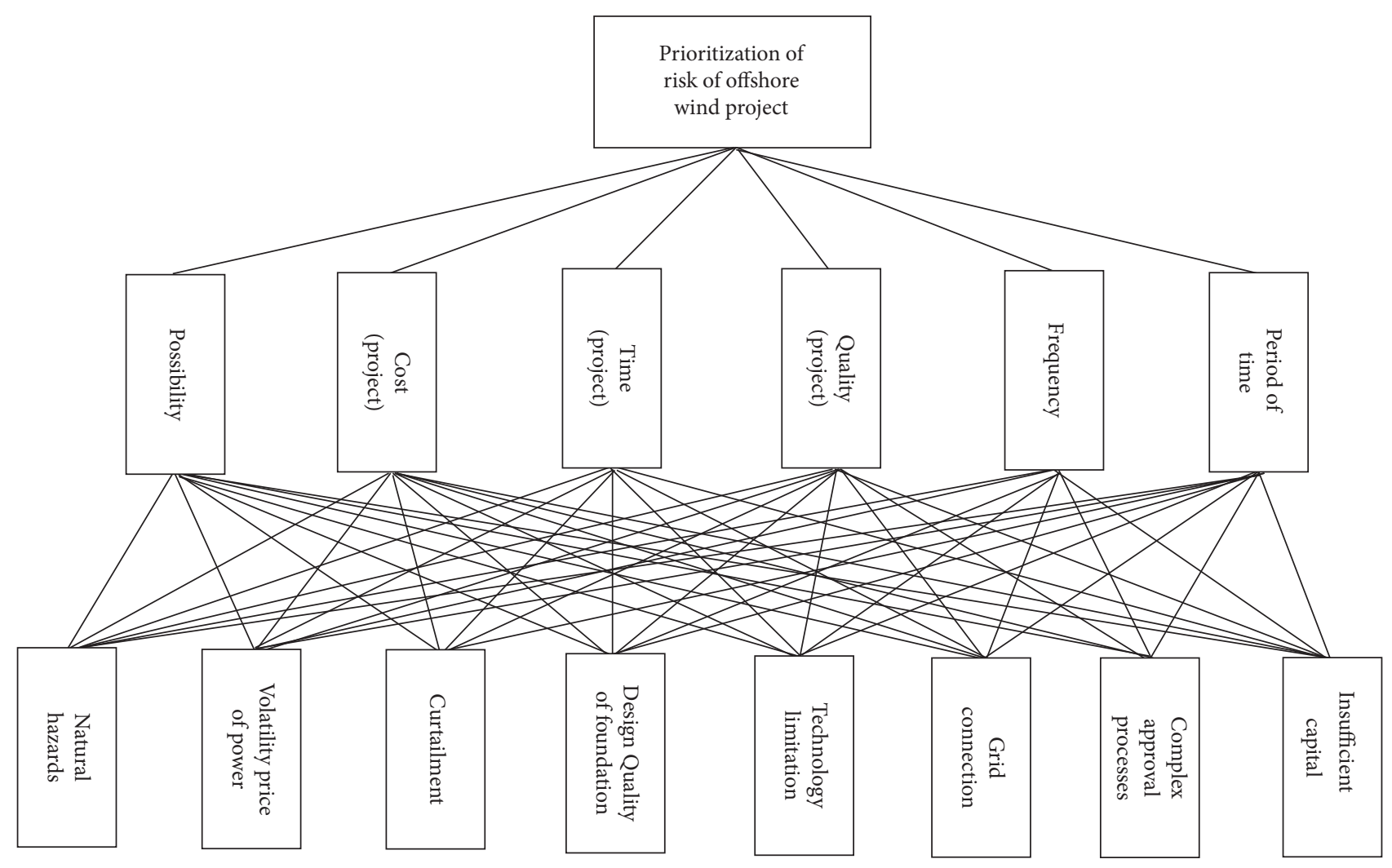

FIGURE 1: Framework for risk analysis in off-shore wind project.

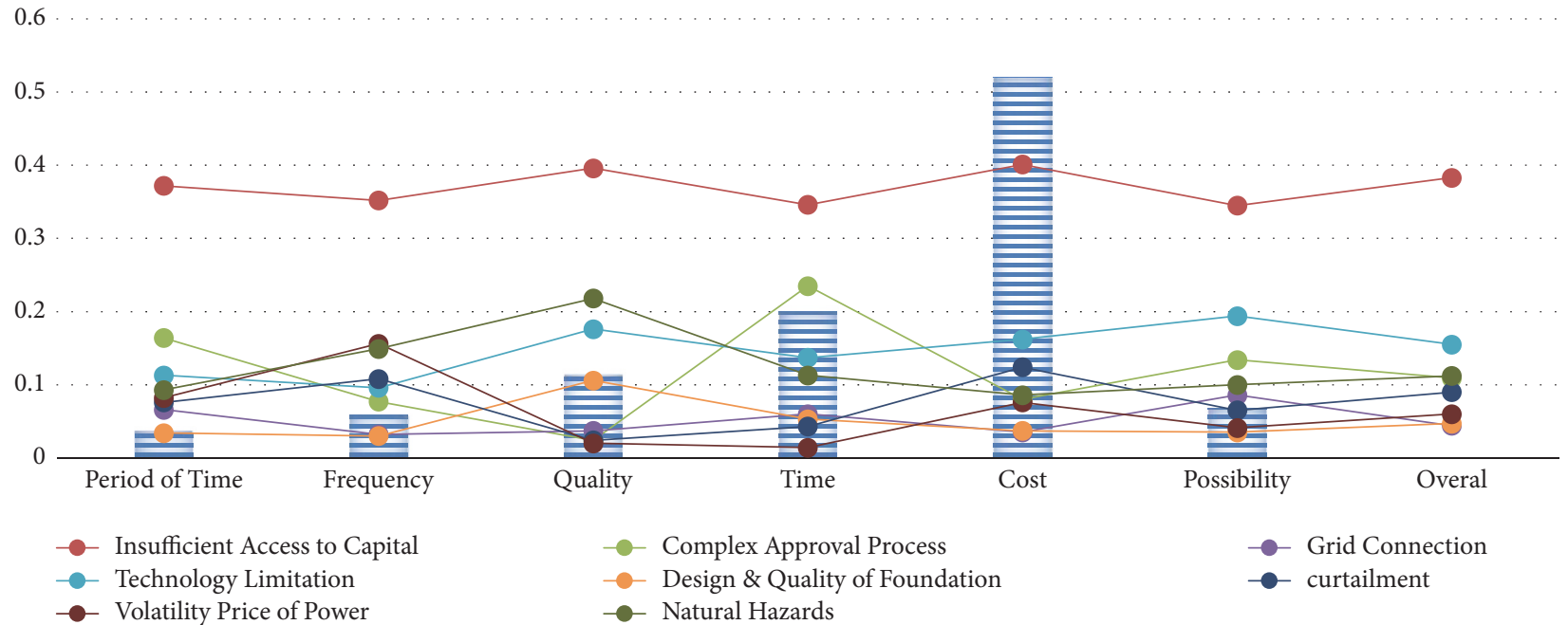

Figure 2: Performance sensitivity alternatives across risk factors.

these risks during the project can be determined. Furthermore the project team learn how to deal with this complex condition and hopefully prevent further complications and secondary risks through the project. This study set up a model of the different risk factors and risks with risk prioritizing objective in a first step which was then evaluated by experts in a second step. The main aim was to discover the weight of risks and risk factors in off-shore wind project and to compare their preferences with expert judgments.

In the first step, a comprehensive model was set up which depicted the different risk factors and risks for evaluating model. Energy experts discussed and successively refined the 


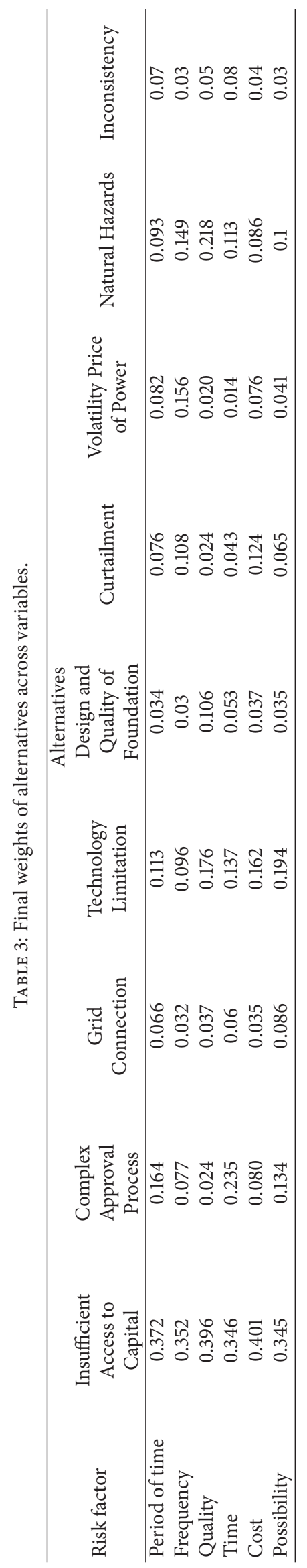


TABLE 4: Final weights of alternatives.

\begin{tabular}{lc}
\hline Alternative & Weight \\
\hline Insufficient Access to Capital & 0.383 \\
Complex Approval Processes & 0.109 \\
Grid Connection & 0.044 \\
Technology Limitation & 0.155 \\
Design and Quality Of Foundation & 0.047 \\
Curtailment & 0.09 \\
Volatility Price of Power & 0.06 \\
Natural Hazards & 0.112 \\
\hline Inconsistency & 0.03 \\
\hline
\end{tabular}

levels of the hierarchies, the number of items, and how to compare and prioritize items.

Secondly, an analytic hierarchy process (AHP) questionnaire was created to elicit experts preferences concerning objective. The questionnaire was pretested and then rolled out for data collection with experts. The questionnaire was distributed on paper between 20 energy experts that specialized, had experience, and worked in wind energy field.

\section{Analysis and Modelling}

2.1. Identify Risks. By reviewing articles specially Gatzert and Kosub [5] and Prostean et al. [6] and reviewing projects, risks in wind energy projects were accomplished in this field and categorized in seven groups as mentioned in Table 1 (Table 1 , risk classification).

2.2. Qualitative Analysis. Qualitative risk analysis is related to two factors: probability and impact.

Risk probability assessment investigates the likelihood that each specific risk will occur. Risk impact assessment investigates the potential effect on a project objective such as time, cost, scope, or quality. The level of probability for each risk and its impact on each objective in this study are evaluated by experts who had experiences in this field. Risks can be prioritized for further quantitative analysis based on their risk rating. Ratings are assigned to risks based on their assessed probability and impact. The first step for performing quantitative analysis is asking experts to score from 1 to 10 for possibility and impact of every risk if this would have happened in project. The next step is calculation of risk coefficient by multiplying possibility and impact of each risk.

Based on the result of qualitative analysis that is performed by experts we can determine high priority risks that affect the project. These risks are (1) insufficient capital, (2) complex approval processes, (3) grid connection, (4) technology limitation, (5) design and Quality of Foundation, (6) curtailment, (7) volatility price of power, and (8) natural hazards.

2.3. Quantitative Analysis. The application of AHP has attracted the attention of many researchers mainly due to the functional mathematical properties of the method and the fact that the required input data are easy to obtain.
AHP is a useful technique of the multicriteria programming for decision-making in complex environments where many variables or criteria are considered in the prioritization and selection of alternatives in the projects.

The comparison between two elements using AHP can be done in different ways. However, the relative importance scale between two alternatives that has been suggested by Saaty is the most widely used method. Attributing values vary from 1 to 9 , and the scale determines the relative importance of an alternative when compared to another alternative [7].

The decision hierarchy is a graphical representation of the main objective, the variables (attributes), and the alternatives. This hierarchic frame and decomposition represent a succinct summary of the decision problem and variables and alternatives. (Figure 1). This figure (Figure 1) demonstrates how AHP can be used to assess variables and alternatives as part of the framework to help the project developers to stay focused on eliminating risk barriers for achieving to the desired goals and finishing the project on time.

In this study expert judgment is used to assess and identify importance scale between alternatives and variables. For this purpose a questionnaire was prepared and distributed among twenty experts and the results were gathered.

To ensure that the data gathered is well defined and accurate, the research team analyzed the present literature $([1,7,8]$ Archer \& Jacobson, 2005).

Decomposition of objective, variables (time, cost, quality, probability, and period of time), and risks which were determined in qualitative analysis comprising insufficient capital, Complex approval processes, Grid connection, Technology limitation, Design and Quality of Foundation, Curtailment, Volatility price of power, and natural hazards was shown in Figure 1.

After decomposing the problem hierarchically, the next step in the process was to pairwise-compare the relative importance of the variables (time, cost, quality, probability, and period of time) as they influence on objective. The relative importance of each risk as driver is that it is associated with risk factor in the next level of the hierarchy.

These comparisons were carried out using the nine-point fundamental scale of the AHP [9].

Risks prioritizing programs are becoming increasingly important in order to offer a comprehensive model for specifying and selecting most important risks that impacted off-shore wind projects.

The judgments with regard to identification of variables and factors, as well as the comparisons of their relative impact and strength, were conducted by the experts.

Certainly, the outcomes are strongly dependent on those judgments.

To determine the reliability of the questionnaires, Cronbach's alpha test, which is more common than other methods, is used in spss software. The use of Cronbach's alpha coefficient can be used to determine the reliability of a questionnaire or test with an emphasis on internal correlation. In this method, the components or parts of the questionnaire are used to measure the reliability of the test. If the alpha coefficient is greater than 0.7 the test has an acceptable reliability. 
Given that the Cronbach's alpha coefficient is 0.78 , the questionnaire has an acceptable reliability.

Generally 239 pair comparisons were conducted comprising 15 pair comparisons for determining relative importance of each variable and 224 pair comparisons for determining relative importance of each risk.

\section{Results and Discussion}

To determine the relative importance of the variables (comprising cost, time, quality, probability, period of time, and frequency) we evaluated pairs of these factors on a 9-point scale by performing questioners and using expert judgments.

This evaluation is done in order to perform a pairwise comparison of variables to specify its relative importance.

For example probability and frequency are compared in pairwise way and which of them is more important during implementation of the project is investigated. Then, they are scored from 1 to 9 (based on their importance).

A formal data collection process was necessary for the evaluation of the variables. To ensure that collected data is accurate, the research team analyzed the present literature ([1]; Chopra).

To determine the relative importance of the variables we evaluated pairs of these factors (attributes) on a 9-point scale that scored from equality important (1) to extremely more important (9). These pairwise comparisons had been done by using questionnaires. In order to reach better results these questionnaires were taken to the experts that had experiences in wind energy project. For calculating final weight of each risk factor 30 pairwise comparisons were conducted and the final weight for each risk factor was represented. Each risk factor representing its relative importance is provided in Table 2. The results presented in Table 2 show that cost $(0.52)$ is most important in relation to other factors because of impact on expenditure of project. The importance of time (0.2) is because of its critical role in scheduling and deadlines. Quality (0.115) could influence deliverables and caused waste and rework. Possibility (0.068), frequency (0.059), and period of time (0.038) are achieved such that each of them could impose more losses to the project.

The final weight for each risk factor that shows its relative importance was represented in Table 2 (Final weight of variables).

As a result of evaluation, the represented cost has more importance compared to other risk factors by 0.52 in that it demonstrates that it has undeniable role in the implementation of wind project in Iran.

The evaluation of the 8 alternatives (the third level of Figure 1) was conducted in a similar way as the comparison among variables.

Matrices were created with the rows and columns being labeled with the 8 alternatives. A modified 9-point scale (Table 1) was used to make the 28 pairwise comparisons per matrix, resulting in total of 168 evaluations.

The final weights of alternatives across variables (Table 3 ) present information about the relative performance of the 8 alternatives across each risk factor; higher values signify more favorable relative performance.
For developing the weight of variables, 15 pairwise comparisons were conducted and also 168 pairwise comparisons for developing the weight of alternatives.

To obtain final evaluation of alternatives, assessing all variables according to the 8 alternatives has been achieved (Table 3), for example, cost (0.52) multiplied by the alternative cost across insufficient access to capital (0.401), Complex Approval Process (0.08), Grid Connection (0.035), Technology Limitation (0.162), Design and Quality of Foundation (0.037), curtailment (0.124), Volatility price of power $(0.076)$, and natural hazards (0.086). The result will be gathered (vertical columns) to get the outcome of each alternative (Table 4).

Insufficient Access to Capital (0.383) could influence on funding activities such as bank loans and attract investment, and Complex Approval Processes (0.109) could influence on licensing \& permitting activities. Grid Connection (0.044) could influence on activities like connections between turbines and onshore and off-shore substations.

Technology Limitation (0.155) could influence on activities such engineering and design turbines (rotor, nacelle, and tower). Design and Quality of Foundation (0.047) could influence on activities related to turbine's foundation.

Curtailment (0.09) influences on assessment required capacity and produces power. Volatility price of power (0.06) influences on produced power. Natural Hazards (0.112) influence on maintenance, turbine foundation, off-shore substation, and onshore substation installation.

Figure 2. (performance sensitivity alternatives across risk factors) show the rate of performance sensitivity according to its weights across each of the risk factors.

Insufficient access to investment has the minimum fluctuations in this fig in comparing other alternative; moreover, it has the most relative important and constant trend compared to other risk factors.

The final results presented in Table 4 show that final weights of alternatives demonstrate the most important risks that developers encounter in off-shore wind energy project in Iran.

\section{Conclusions}

Growth in the wind energy sector has recently been increased and developed in the world. In this regard, identification of the most important risk is critical to construct an off-shore wind farm and needs to consider multiple criteria.

In this study, we demonstrated that it is possible to utilize AHP as the multicriteria decision-making method for the prioritization of the risks of off-shore wind project. Consistency ratios calculated throughout the analysis are in acceptable limits, showing the legitimacy of the results. Below results can be drawn from the analysis in the present paper:

(1) The risks of off-shore wind project as a result of the exhaustive study were investigated through six main criteria; period of time, frequency, quality, time, cost, and possibility. 
(2) A qualitative assessment was made and then prioritizing the eight critical risks of lack of capital, verification processes, network connectivity, technology constraints, design and quality of the foundation, demand changes, price fluctuations, and natural hazards by the analysis hierarchy method was launched.

(3) With the ultimate purpose of prioritizing the risks and trying to determine the most critical criteria and risks, all the criteria are examined by AHP.

(4) Cost is the most significant criteria considering the prioritization of off-shore wind project.

(5) From the perspective of period of time, frequency, quality, time, cost, and possibility effects, the most critical risk was observed to be the insufficient access to capital.

For prioritizing, the important risks that deal with off-shore wind project are listed and categorized based on interviews with experts and literature review and they are used to establish a decision-making model with six main criteria. Although the risks associated with off-shore wind energy in Persian Gulf in Iran are used to apply in this study, a robust model is developed so it can be applied for all cases related to environment, geographical location, regulation, and so on. Determining the related risks and grouping them in different categories is another contribution provided by this research. The results are significant both from feasible and economic perspective as the useful methodology is practically implementable and viable.

Then the weight of the variables is specified, in order to determine the weight of the alternatives (critical risks); these options were compared in paired tiers, taking into account the relevant variables in the higher level, and the weight of each of the alternative was determined.

With AHP, prioritization of risks for each project and in each industry with different variables and options would determine the significance of risks, so that project developers can focus on the risks that have the greatest impact on cost, time, and quality of the project. Also it could determine contingency reserve and appropriate strategy to confront them.

\section{Nomenclature}

AHP: Analytic Hierarchy Process

EMV: $\quad$ Expected Monetary Value

PMBOK: Project Management Body of Knowledge.

\section{Conflicts of Interest}

The authors declare that they have no conflicts of interest.

\section{References}

[1] M. I. Blanco, “The economics of wind energy," Renewable \& Sustainable Energy Reviews, vol. 13, no. 6-7, pp. 1372-1382, 2009.

[2] Z. Shirgholami, S. Namdar Zangeneh, and M. Bortolini, "Decision system to support the practitioners in the wind farm design: a case study for Iran mainland," Sustainable Energy Technologies and Assessments, vol. 16, pp. 1-10, 2016.
[3] L. Sagbansua and F. Balo, "Decision making model development in increasing wind farm energy efficiency," Journal of Renewable Energy, vol. 109, pp. 354-362, 2017.

[4] A. Chaouachi, C. F. Covrig, and M. Ardelean, "Multi-criteria selection of offshore wind farms: Case study for the Baltic States," Energy Policy, vol. 103, pp. 179-192, 2017.

[5] N. Gatzert and T. Kosub, "Risks and risk management of renewable energy projects: The case of onshore and offshore wind parks," Renewable \& Sustainable Energy Reviews, vol. 60, pp. 982-998, 2016.

[6] G. Prostean, A. Badea, C. Vasar, and P. Octavian, "Risk variables in wind power supply chain," Procedia - Social and Behavioral Sciences, vol. 124, pp. 124-132, 2014.

[7] T. Schoenherr, V. M. Rao Tummala, and T. P. Harrison, "Assessing supply chain risks with the analytic hierarchy process: Providing decision support for the offshoring decision by a US manufacturing company," Journal of Purchasing and Supply Management, vol. 14, no. 2, pp. 100-111, 2008.

[8] S. Chopra and M. S. Sodhi, "Managing risk to avoid: supplychain breakdown," MIT Sloan Management Review, vol. 46, no. 1, pp. 53-61, 2004.

[9] T. L. Saaty and L. G. Vargas, "Uncertainty and rank order in the analytic hierarchy process," European Journal of Operational Research, vol. 32, no. 1, pp. 107-117, 1987. 


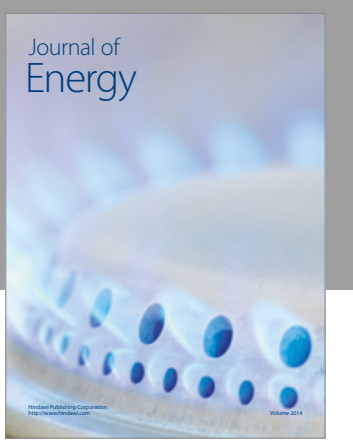

Journal of

Industrial Engineering
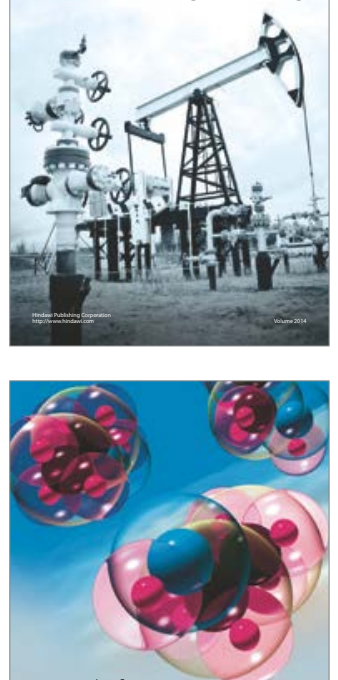

Fuels
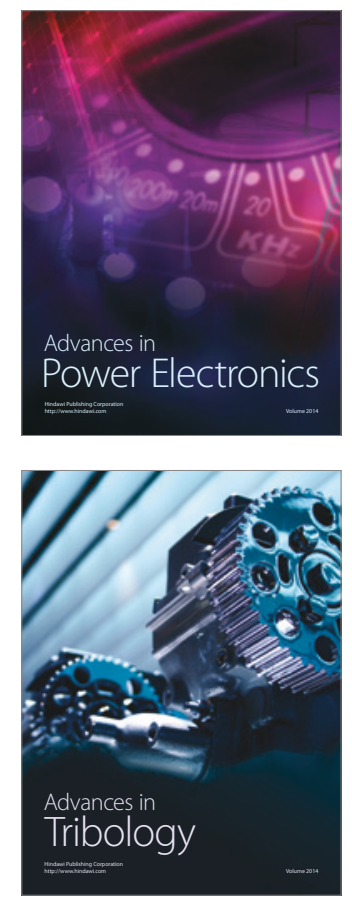
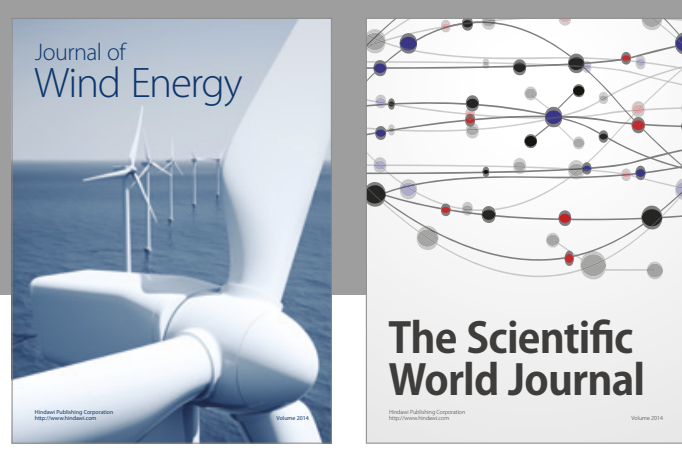

The Scientific World Journal
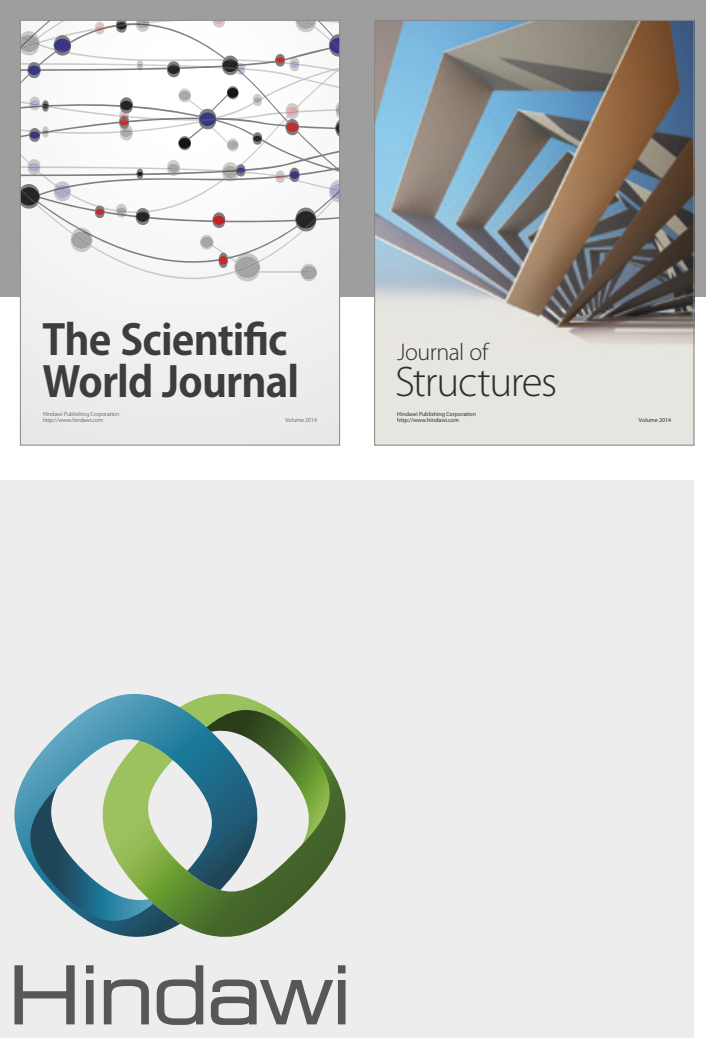

Submit your manuscripts at

https://www.hindawi.com
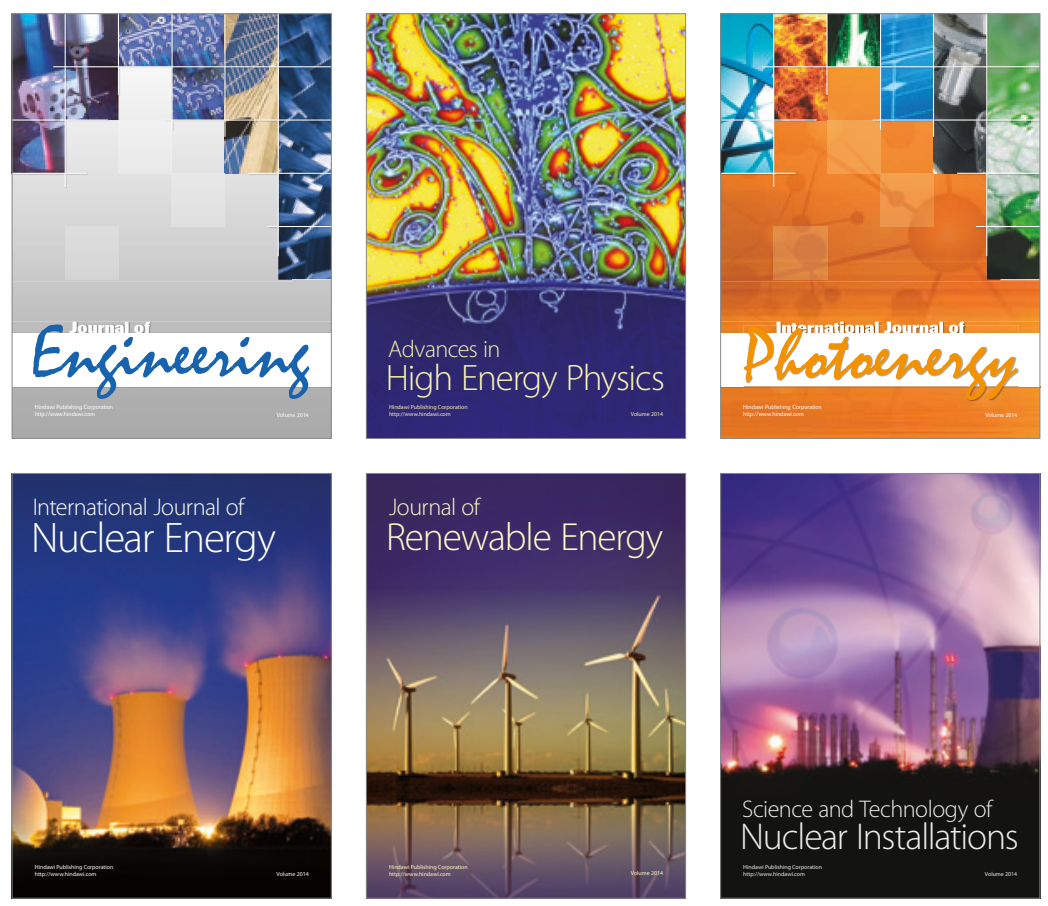

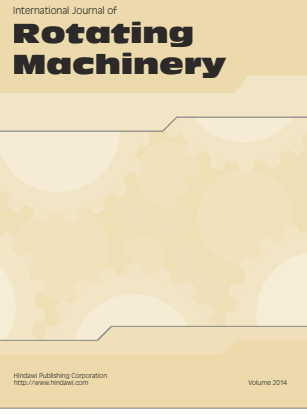

Journal of

Petroleum Engineering

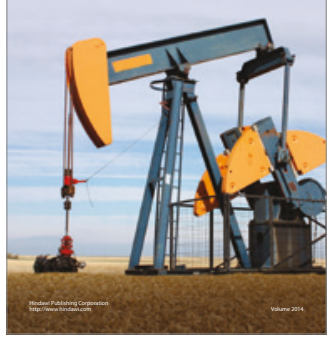

Journal of
Solar Energy
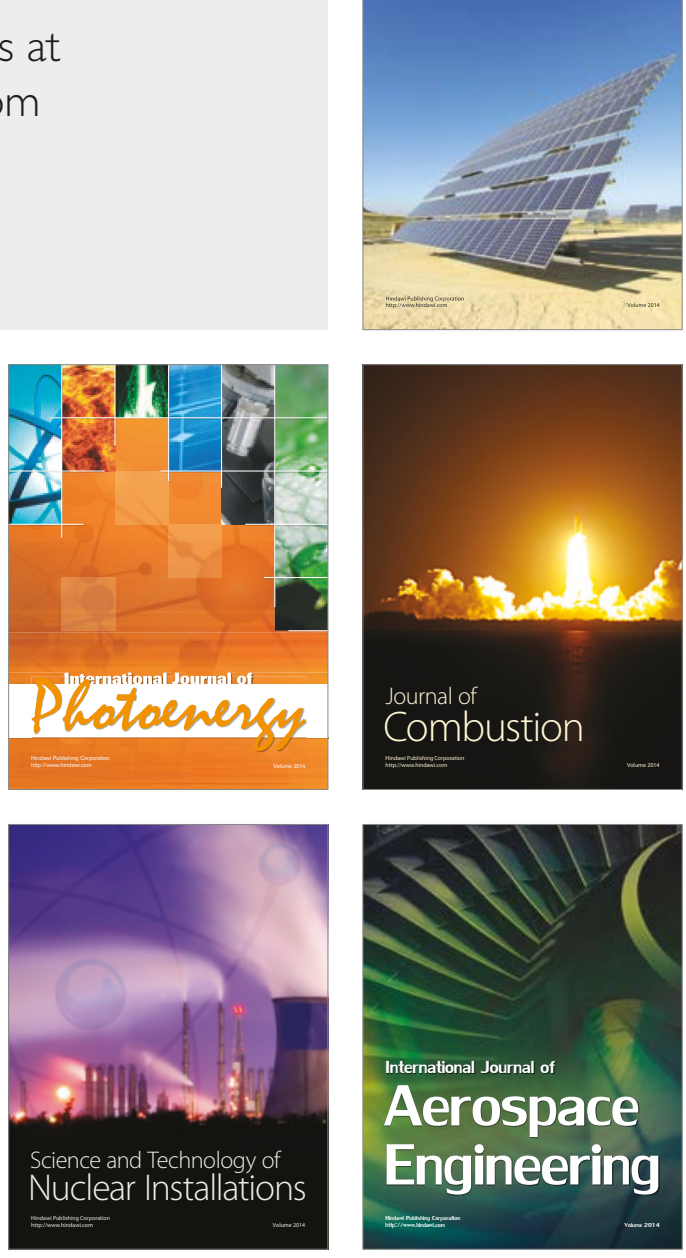